\title{
BNIP3/Bcl-2-mediated apoptosis induced by cyclic tensile stretch in human cartilage endplate-derived stem cells
}

\author{
CHAO YUAN*, LUQIAO PU* ${ }^{*}$ ZHILIANG HE and JIAN WANG \\ Department of Orthopaedics, Xinqiao Hospital, The Third Military Medical University, Chongqing 400037, P.R. China
}

Received March 17, 2017; Accepted August 24, 2017

DOI: $10.3892 /$ etm.2017.5372

\begin{abstract}
The present study aimed to investigate the molecular mechanisms of cyclic stretch-induced apoptosis in human intervertebral disc cartilage endplate-derived stem cells (CESCs). CESCs were stretched by the Flexercell-4000 ${ }^{\mathrm{TM}}$ Tension Plus system, the effect on cell viability was measured by a Cell Counting Kit- 8 assay, while cell apoptosis was detected by flow cytometry. Western blot analysis was used to evaluate the expression of B-cell lymphoma 2 (Bcl-2)/adenovirus E1B $19 \mathrm{kDa}$ interacting protein 3 (BNIP3), Bcl-2, Bcl-2 homologous antagonist killer (Bak), Bcl-2-associated X protein (Bax), $\mathrm{Bcl}$ extra large (Bcl-xl) and the activity of caspase-3, while Z-VAD-FMK was used to inhibit caspase-3. Compared with the control group, the cell viability decreased in a time-dependent manner after stretching. Furthermore, cell apoptosis and the activity of caspase- 3 were increased in a time-dependent manner. The ratio of pro-death factor BNIP3 to anti-apoptotic protein $\mathrm{Bcl}-2$ was significantly increased. When cells were stretched for $36 \mathrm{~h}$, the apoptosis-associated proteins Bak and Bax were increased, while Bcl-xl was decreased. The viability and apoptotic ratio of stretched cells were significantly restored after caspase-3 was repressed. In conclusion, cyclic tensile stretch induced apoptosis of CESCs, which was probably due to upregulation of the expression of BNIP3.
\end{abstract}

\section{Introduction}

Lower back pain (LBP) is one of the most common orthopedic problems, and is associated with high cost for medical health and social care $(1,2)$. Intervertebral disc degeneration (IDD) has long been considered to have an important role in

Correspondence to: Professor Jian Wang, Department of Orthopaedics, Xinqiao Hospital, The Third Military Medical University, 183 Xinqiao Street, Shapingba, Chongqing 400037, P.R. China

E-mail:wjxinqiao@outlook.com

${ }^{*}$ Contributed equally

Key words: cartilage endplate-derived stem cells, stretch, apoptosis, B-cell lymphoma 2/adenovirus E1B $19 \mathrm{kDa}$ interacting protein 3 the pathogenesis of LBP (3), although other causes have also been suggested $(4,5)$. Several factors are thought to cause IDD, including genetic factors (6), abnormal mechanical loading (7) and poor disc cell nutrition (8). Intervertebral discs (IVDs) have three major components, namely nucleus pulposus, annulus fibrosus and two thin hyaline cartilage endplates (CEPs) situated between the disc and the adjacent vertebral bodies. IVD scontain the largest amount of avascular tissue in the body and nutrient supply to mature disc cells is almost entirely reliant on the diffusion through CEPs (9). Therefore, the morphological integrity and physiological function of the CEPs are essential for the maintenance of the IVDs, and adequate transport is critical for their health. It is increasingly recognized that functional disorders of CEPs have an important role in the process of IDD (10). However, the role of CEP degeneration in this process and the underlying mechanisms have remained elusive.

Apoptosis is a type of programmed cell death, which has an important role in homeostasis, normal development and elimination of potentially pathological cells from the organism (11). Inappropriate regulation of apoptosis may lead to various pathological conditions, including cancer, stroke, ischemia and neurodegenerative diseases (12). Gruber and Hanley (13) assessed apoptosis in human intervertebral disc annulus fibrosus by a terminal deoxynucleotidyl transferase deoxyuridine triphosphate nick end labeling assay and identified that apoptosis was associated with patient age. Ariga et al (14) confirmed that apoptosis also occurred in cartilage endplates and that mechanical stress was an important factor affecting disc cell apoptosis and disc degeneration. However, the mechanisms of stress-induced apoptosis in intervertebral discs have remained to be fully elucidated.

A previous study by our group identified stem cells in human degenerated CEPs, which were named as CEP stem cells (CESCs) (15). The present study investigated the effects of cyclic tensile stretch on the apoptosis of CESCs and investigated the underlying molecular mechanisms.

\section{Materials and methods}

Ethics statement. Institutional Review Board approval and informed consent for sample collection were obtained prior to the collection of all samples. All of the procedures specified below were approved by the Ethical Committee of Xinqiao Hospital (the Third Military Medical University, Chongqing, China) and were in accordance with the Helsinki Declaration. 
Cell culture and investigation of surface markers. Human intervertebral disc cartilage endplate cells and CESCs were obtained from 6 patients (3 men, 3 women; 39-50 years old), following the protocol of a previous study (15). Cells were derived from surgically resected intervertebral disc cartilage endplate. CESCs at passage 3 were used in the present study. The expression profile of cell surface antigens was determined by flow cytometry. In brief, the cells were seeded in a 6-well culture plate and grown until they reached $90 \%$ confluence. After washing with PBS, the cells were stained with the following fluorescein isothiocyanate (FITC), phycoerythrin (PE) or peridinin chlorophyll protein (PerCP)-conjugated antibodies: CD73-FITC (cat. no. 11-0739-41), CD14-FITC (cat. no. 11-0149-41), CD19-FITC (cat. no. 11-0199-41), CD90-FITC (cat. no. 11-0909-41), CD34-FITC (cat. no. 11-0349-41), CD45-FITC (cat. no. 11-9459-41), CD105-PE (cat. no. 12-1057-41) or human leukocyte antigen - antigen D related (HLA-DR)-PerCP(cat. no. 9043-4724-025) (1:500 dilution, all from eBioscience; Thermo Fisher Scientific, Inc., Waltham, MA, USA). Immunoglobulin G (eBioscience; Thermo Fisher Scientific, Inc.) was used as an isotype control. After incubation for $30 \mathrm{~min}$ at $37^{\circ} \mathrm{C}$, cells were washed 3 times with PBS and resuspended in $200 \mu \mathrm{l}$ PBS. Finally, labeled cells were subjected to single-channel flow cytometric analysis (BD Biosciences, Franklin Lakes, NJ, USA). The percentage of stained cells was calculated relative to the isotype control.

Application of cyclic tension to cultured cells. For cyclic tension loading, CESCs were placed on an elastic silicone membrane coated with collagen I at a density of $2 \times 10^{5}$ cells per well. After reaching 80-90\% confluence, cells were serum-starved in Dulbecco's modified Eagle's medium (DMEM)/F12 (Gibco; Thermo Fisher Scientific, Inc.) containing 1\% fetal bovine serum (FBS) (Gibco; Thermo Fisher Scientific, Inc.) for $24 \mathrm{~h}$ for synchronization, followed by stretching using a Flexercell ${ }^{\mathrm{TM}}$ Tension Plus system (FX-4000T; Flexcell International Corp., Burlington, $\mathrm{NC}, \mathrm{USA}$ ) at $37^{\circ} \mathrm{C}$ in a $5 \% \mathrm{CO}_{2}$ incubator in DMEM/F12 with $10 \%$ FBS. According to the experimental protocol, a $20 \%$ stretch elongation at a frequency of $1 \mathrm{~Hz}$ was applied for 12, 24, 36 or $48 \mathrm{~h}$.

Cell viability detection and caspase-3 repression assay. After stretching, cells were seeded into 96-well plates at a density of $5 \times 10^{3}$ cells per well. After $24 \mathrm{~h}$, the cell viability was assessed using a Cell Counting Kit-8 (CCK-8) according to the manufacturer's instructions. In brief, $10 \mu \mathrm{l}$ CCK- 8 solution was added to each well and the plate was then incubated at $37^{\circ} \mathrm{C}$ for $4 \mathrm{~h}$. The optical density was measured at a wavelength of $450 \mathrm{~nm}$ with a microplate reader. In another experiment prior to stretching, caspase-3 inhibitor Z-VAD-FMK $(20 \mu \mathrm{M}$; Beyotime Institute of Biotechnology, Haimen, China) was added to the cell culture medium and the plate was incubated at $37^{\circ} \mathrm{C}$ for $20 \mathrm{~min}$.

Detection of apoptotic rate by flow cytometry. The apoptotic rate was measured with an Annexin V-FITC apoptosis detection kit I (BD Pharmingen, Franklin Lakes, NJ, USA) according to the manufacturer's instructions. In brief, cells were washed twice with cold PBS and then resuspended in $300 \mu \mathrm{l}$ binding buffer at a concentration of $1 \times 10^{6}$ cells per $\mathrm{ml}$.
Annexin V-FITC solution (5 $\mu \mathrm{l})$ and propidium iodide (PI; $5 \mu \mathrm{l}$ of a $1 \mu \mathrm{g} / \mathrm{ml}$ solution) were then added to these cells, followed by incubation for $30 \mathrm{~min}$ at $37^{\circ} \mathrm{C}$. The apoptotic incidence was detected by flow cytometry within $1 \mathrm{~h}$.

Caspase-3 activity detection assay. Caspase-3 activity was detected with a caspase assay kit (Beyotime Institute of Biotechnology) according to the manufacturer's protocol. In brief, $2 \times 10^{6}$ cells were lysed with $100 \mu 1$ lysis buffer on ice for $15 \mathrm{~min}$ and the cell lysates were then centrifuged at $16,000 \mathrm{x} \mathrm{g}$ for $10 \mathrm{~min}$ at $4^{\circ} \mathrm{C}$. Reaction buffer $(80 \mu \mathrm{l})$ and acetyl-DEVD-p-nitroanilin (pNA; $10 \mu \mathrm{l}$ ) was mixed with $10 \mu \mathrm{l}$ lysate and the mixture was then incubated for $2 \mathrm{~h}$ at $37^{\circ} \mathrm{C}$. The optical density of free pNA was measured at an absorption wavelength of $405 \mathrm{~nm}$ using a microplate spectrophotometer (Dynex Technologies, Chantilly, VA, USA). Caspase-3 activity was expressed as the relative absorbance ratio of samples vs. control group.

Western blot analysis. Cells were lysed using lysis buffer containing $1 \mathrm{mM}$ phenylmethylsulfonylfluoride (Beyotime Institute of Biotechnology), Protein concentration was determined with the BCA Protein Assay kit (Beyotime Institute of Biotechnology). Equal amounts of protein $(30 \mu \mathrm{g})$ were separated by $12 \%$ SDS-PAGE and transferred onto polyvinylidene diflouride membranes (Bio-Rad Laboratories, Inc., Hercules, CA, USA). Subsequently, the membrane was blocked in $5 \%$ non-fat milk and $0.1 \%$ Tween-20 containing Tris-buffered saline (TBST) at room temperature for $1 \mathrm{~h}$ and then incubated with the respective primary antibodies overnight at $4^{\circ} \mathrm{C}$. After washing with TBST, the membrane was then incubated with appropriate horseradish peroxidase-conjugated secondary antibodies at room temperature for $2 \mathrm{~h}$. Immunoblotting was detected by enhanced chemiluminescence (BeyoECLPlus, Beyotime, Beijing, China) and images of blots were captured on a ImageQuant LAS4010 (GE Healthcare, Little Chalfont, UK). Western blot bands were quantified using ImageJ software (ImageJ 1.41; National Institutes of Health, Bethesda, NJ, USA). The primary antibodies used for western blot analysis were as follows: B-cell lymphoma 2 (Bcl-2)/adenovirus E1B $19 \mathrm{kDa}$ interacting protein 3 (BNIP3) (cat. no. ab10433; mouse monoclonal), Bcl-2 (cat. no. ab59348; rabbit monoclonal), Bcl-2 homologous antagonist killer (Bak; cat. no. ab69404; rabbit monoclonal), Bcl-2-associated X protein (Bax; cat. no. ab53154; rabbit monoclonal) and Bcl extra large (Bcl-xl; cat. no. ab32370; rabbit monoclonal) (all used at 1:500 dilution; Abcam, Cambridge, MA, USA) and GAPDH (cat. no. TA-08, 1:2,000 dilution; Beijing Zhongshan Goldenbridge Biotechnology Co., Ltd., Beijing, China). The secondary antibodies used in the present study were as follows: Horse radish peroxidase (HRP)-labeled goat anti-mouse (cat. no. A0216) and anti-rabbit (cat. no. A0208) Immunoglobulin G (IgG) (H+L) (all 1:1,000 dilution; Beyotime Institute of Biotechnology).

Statistical analysis. Data were analyzed using SPSS 13.0 statistical software (SPSS, Inc., Chicago, IL, USA). Values are expressed as the mean \pm standard deviation. Differences between groups were assessed using the one-way analysis of variance and the Least Significant Difference test. $\mathrm{P}<0.05$ was considered to indicate a statistically significant difference. 

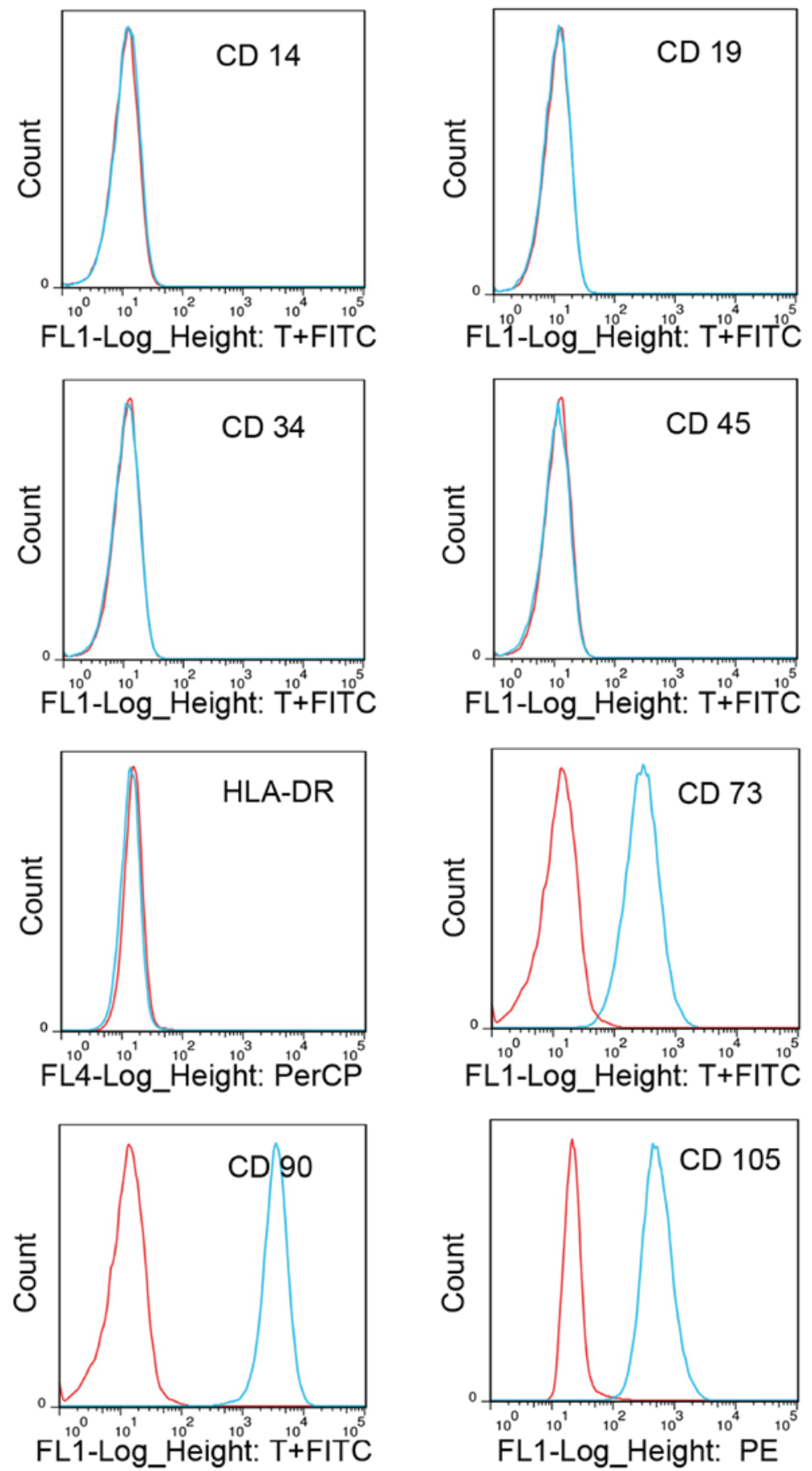

Figure 1. Immunophenotypic profile of cultured cartilage endplate-derived stem cells. The blue lines represent the fluorescence intensity of cells stained with the indicated antibodies and the red lines represent the negative controls cells, which were stained with a non-immunoreactive isotype control antibody. FITC, fluorescein isothiocyanate; PerCP, peridinin chlorophyll; PE, phycoerythrin; HLA-DR, human leukocyte antigen-antigen D related.

\section{Results}

Surface antigen profile of CESCs. The surface antigens of CESCs were investigated in passage 3 cells. Flow cytometric analysis revealed that the CESCs were negative for CD14, CD19, CD34, CD45 and HLA-DR, but positive for CD73, CD90 and CD105 (Fig. 1), which was similar to the result of a previous study by our group (15). Considering that the pluripotency of CESCs has already been demonstrated in a previous study (15), these results indicated that the cells used in the present study possessed the properties of stem cells.
Effects of stretch on the viability and apoptosis of CESCs. The effects of a tensile stretch on the viability of CESCs were assessed. After $20 \%$ stretch elongation at a frequency of $1 \mathrm{~Hz}$ for $12,24,36$, or $48 \mathrm{~h}$, the viability of CESCs was assessed using a CCK-8. The results demonstrated that compared with static control cells $(0 \mathrm{~h})$, the viability of CESCs decreased with the increase of stretching time $(\mathrm{P}<0.05$; Fig. $2 \mathrm{~A})$.

Furthermore, it was assessed whether the decrease in viability of CESCs was due to apoptosis. The apoptotic rate was detected by flow cytometry with Annexin V and PI double labeling. PI labels all dead cells, including necrotic cells and 

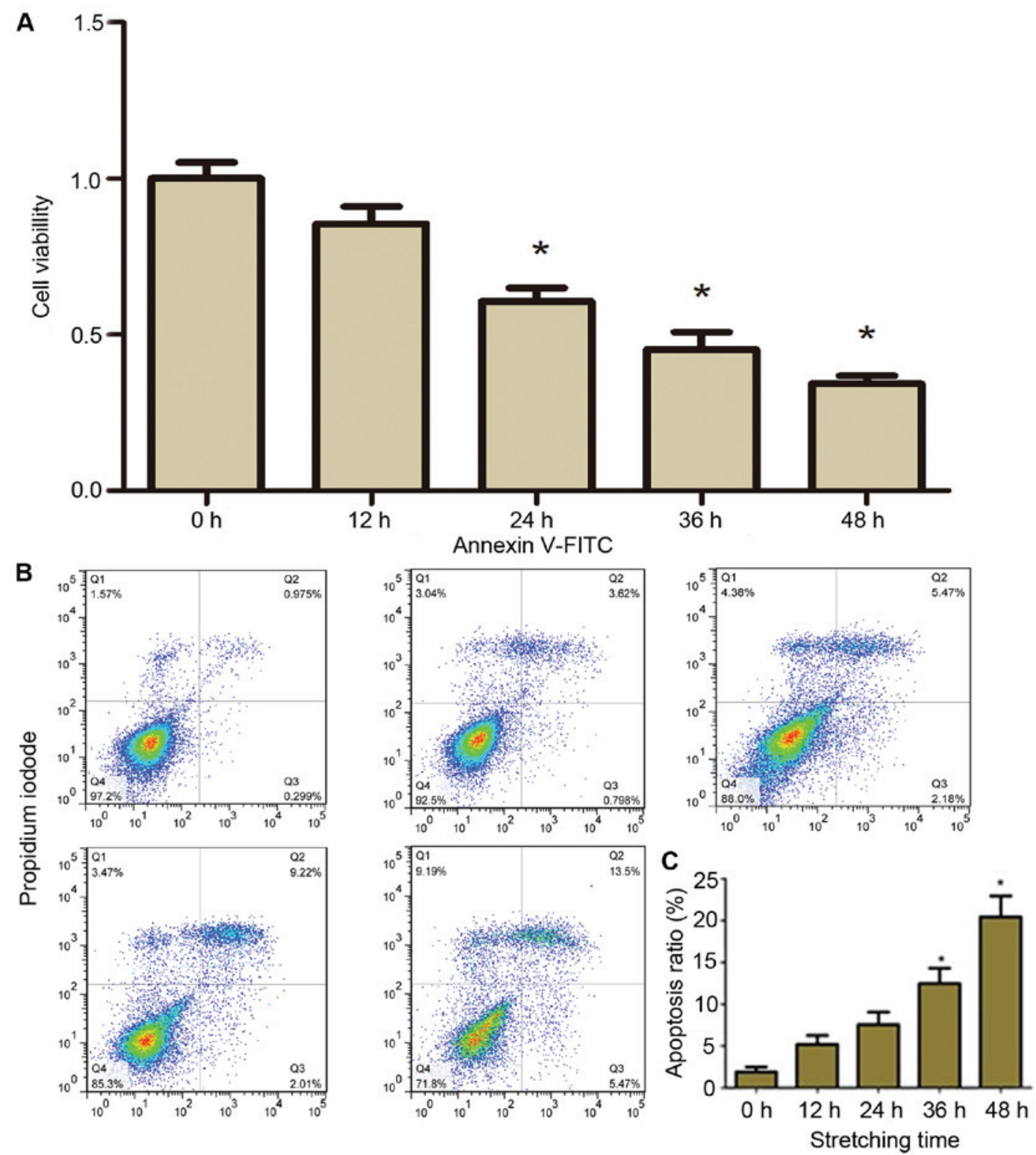

Figure 2. Effects of cyclic stretch on the viability and apoptosis of CESCs. CESCs were subjected to a $20 \%$ stretch at a frequency of $1 \mathrm{~Hz}$ for $12,24,36 \mathrm{or} 48 \mathrm{~h}$. (A) The cell viability was assessed using a Cell Counting Kit-8 assay. (B) Apoptosis was detected by flow cytometry using an Annexin V/PI assay. Representative flow cytometric dot plots obtained after double-staining with Annexin V-FITC and PI are presented. (C) Apoptotic indices from (B). Static CESCs (0 h) were used as a control. ${ }^{~} \mathrm{P}<0.05$ vs. control group. CESCs, cartilage endplate-derived stem cells; FITC, fluorescein isothiocyanate; PI, propidium iodide.

those at the final stages of apoptosis, whereas cells in early apoptosis were only stained with Annexin V. Representative graphs obtained by flow cytometric analysis of cells after Annexin V-FITC and PI double staining are presented in Fig. 2B. The apoptotic incidence in the static control group was $1.27 \%$. The results demonstrated that the apoptotic incidence was significantly increased in CESCs subjected to cyclic stretch compared to that in the control group in a time-dependent manner (Fig. 2B). Hence, the apoptotic incidence in the CESCs was increased to 5.12, 7.06, 12.06 and $20.00 \%$ after cyclic stretch for $12,24,36$ and $48 \mathrm{~h}$, respectively (Fig. 2C). These results demonstrated that a cyclic tensile stretch decreased the viability and increased the apoptotic rate of CESCs.

Effect of stress on the activity of caspase-3. Since cyclic stretch increased cell apoptosis in a time-dependent manner, the apoptotic mechanism in CESCs was then assessed. In order to understand whether apoptosis induced by cyclic stretch was caspase-dependent, the activity of caspase- 3 was measured. The results indicated that the activity of caspase- 3 in cells subjected to cyclic stretch increased in a time-dependent manner compared with that in static control cells (Fig. 3A), which was consistent with the apoptosis incidence (Fig. 3B and $\mathrm{C}$ ). This finding suggested that cyclic stretch activated caspase-3 in CESCs, which finally induced cell apoptosis.

Effect of stress on the expression of BNIP3 and Bcl-2 in CESCs. To further investigate the molecular mechanism of cyclic stretch-induced apoptosis, the expression of BNIP3 and Bcl-2 in CESCs was assessed. As presented in Fig. 3B, compared with the static control cells, the expression of pro-apoptotic protein BNIP3 increased in cells subjected to $20 \%$ stretch elongation at a frequency of $1 \mathrm{~Hz}$ for 12,24 , 
A

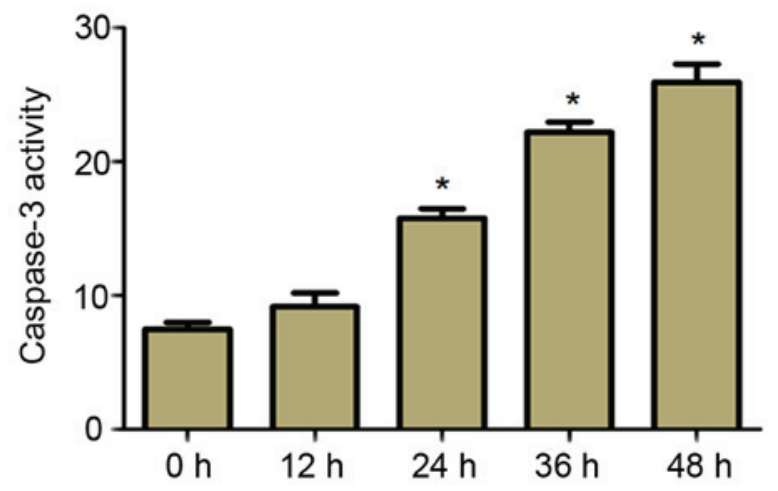

B
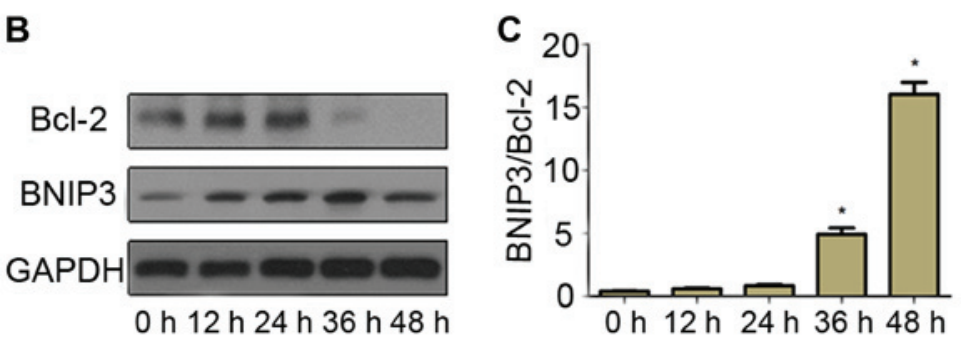

Figure 3. Effect of stress on the activity of caspase-3 and the expression of apoptosis-associated proteins. CESCs were subjected to a $20 \%$ stretch at a frequency of $1 \mathrm{~Hz}$ for different durations $(12,24,36$ or $48 \mathrm{~h}$ ). (A) Caspase-3 activity assay. (B) Western blot analysis was performed to analyze the expression of Bcl-2 and BNIP3 GAPDH was used as a loading control. Representative western blot images are presented. (C) Quantification of the BNIP3/Bcl-2 ratio from (B). Static CESCs (0 h) were used as a control. ${ }^{*} \mathrm{P}<0.05$ vs. control group. CESCs, cartilage endplate-derived stem cells; Bcl-2, B-cell lymphoma 2; BNIP3, Bcl-2/adenovirus E1B $19 \mathrm{kDa}$ interacting protein 3.

36 and 48 h. Furthermore, the expression of anti-apoptotic protein Bcl-2 began to decrease after cells had been subjected to a $20 \%$ stretch elongation for $36 \mathrm{~h}$ (Fig. 3C). These results suggested that upregulation of BNIP3 and downregulation of Bcl-2 probably contributed to apoptosis induced by cyclic stretch in CESCs.

Caspase-3 inhibitor prevents stretch-induced apoptosis. To identify the role of apoptosis in cells exposed to cyclic stretch, caspase-3 was repressed to evaluate cell viability and apoptosis. As presented in in Fig. 4A and B, pro-apoptotic protein Bak and Bax were significantly increased after cells were subjected to a $20 \%$ stretch for $36 \mathrm{~h}$, while Bcl-xl was decreased, which indicated marked apoptosis in the cells. When the caspase-3 inhibitor was added to the cell culture medium, the caspase-3 activity in the stretched cells restored to near basal levels (Fig. 4C), and the cell viability in the stretched cells (Fig. 4D) was also restored comparing with stretched cells without caspase-3 inhibitor. Cell apoptosis (Fig. 4E and F) was also significantly reduced compared with those in stretched cells without caspase-3 inhibitor treatment.

\section{Discussion}

Intervertebral discs have an important buffering function in the human body, and are also the basic structure facilitating spinal movement. Homeostasis in the synthesis and degradation of extracellular matrix is necessary for the normal physiological structure and function of intervertebral discs. When this balance is broken, intervertebral disc degeneration occurs (16). The cartilage endplate is a thin and transparent type of cartilage, which maintains the integrity and physiological function of the intervertebral disc. A previous study indicated that with increasing age of individuals, the morphology of the cartilage endplate changes, which is closely associated with pathological changes in the nucleus pulposus and annulus fibrosus (17). Sowa and Agarwal (18) reported that a moderate cyclic stretch loading decreased the catabolism level and protected intervertebral discs, while an excessive stretch induced cell apoptosis and intervertebral disc degeneration. However, the mechanisms of stretch-induced cell apoptosis in intervertebral discs have remained elusive.

BNIP3 is a member of Bcl-2 protein family and has a single Bcl-2 homology 3 (BH3) domain and is a pro-apoptotic protein in the mitochondrial apoptotic pathway. BNIP3 expression is low in various cell types, where it is primarily localized to the cytoplasm. However, under hypoxia, BNIP3 expression increases, followed by translocation from the cytoplasm to the mitochondria through inserting its C-terminus in the outer mitochondrial membrane (19). After membrane insertion, BNIP3 mediates mitochondrial dysfunction to induces cell apoptosis (20). While BNIP3 is overexpressed in hypoxia, knockdown of BNIP3 expression was reported to reduce hypoxic death of glioblastoma, which are malignant brain tumor cells (21). Another study reported that BNIP3 knockout cells are protected from mitochondrial damage and cell death induced by mutant huntingtin, a key protein associated with Huntington's disease (HD). Deletion of the C-terminal transmembrane domain-encoding region from the BNIP3 gene suppressed mitochondrial depolarization and fragmentation in a cell culture model of HD (22). Bcl-2 family members may interact with the C-terminal domain of BNIP3 to form heterodimers, which was observed to inhibit the translocation of BNIP3 and induce apoptosis (23). BNIP3 inhibits the anti-apoptotic effects of $\mathrm{Bcl}-2$ by interacting with it through its BH3 domain (20). Caspases are a family of 

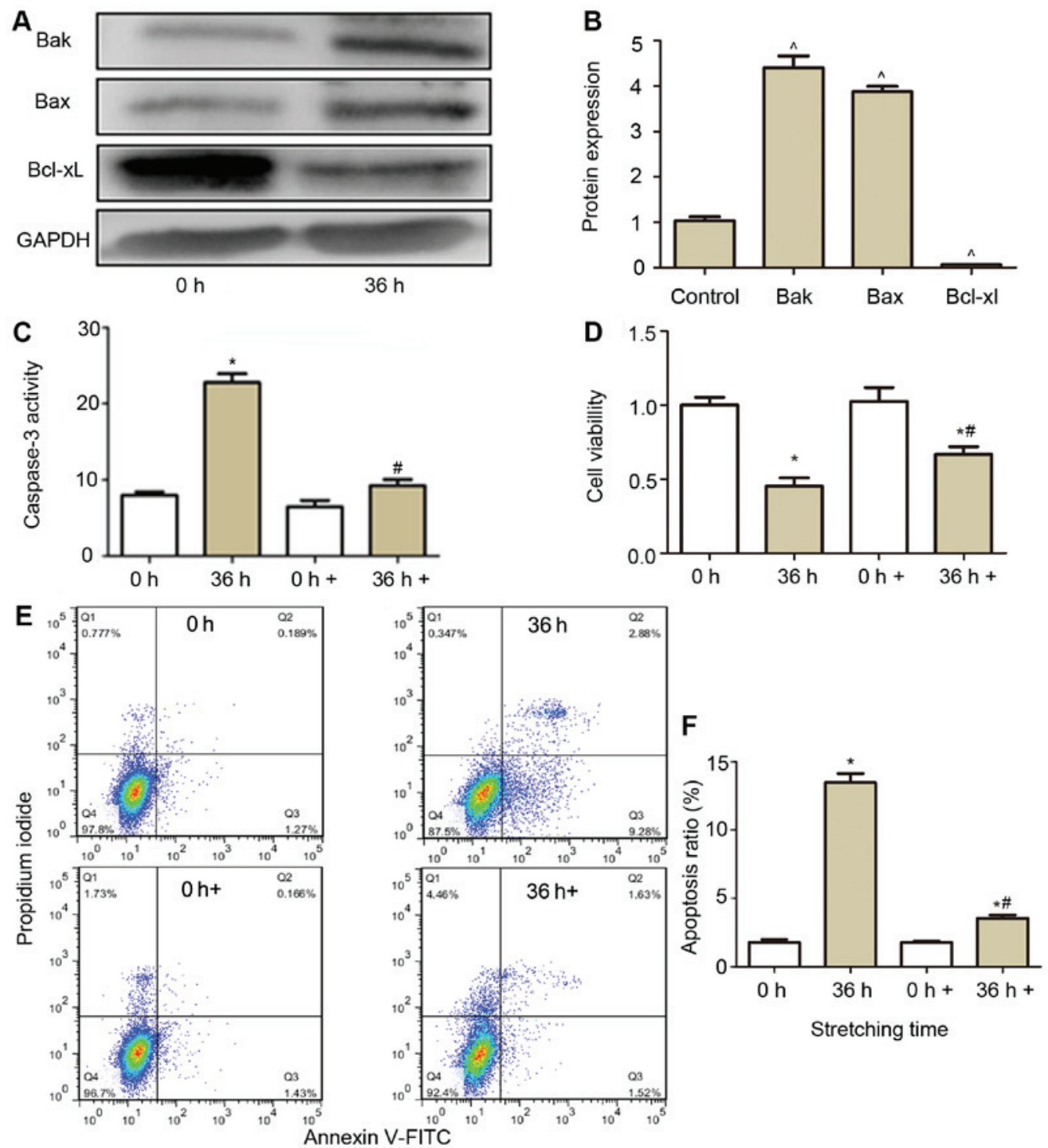

Figure 4. Effect of caspase-3 inhibitor on the activity of caspase-3, cell viability and apoptosis of CESCs subjected to a $20 \%$ stretch at a frequency of $1 \mathrm{~Hz}$ for $36 \mathrm{~h}$. (A) Western blot analysis was performed to analyze the expression of Bak, Bax and Bcl-xl. GAPDH was used as a loading control. (B) Quantification of the expression of Bak, Bax and Bcl-xl from (A). (C) Effect of caspase-3 inhibition (0 and $36 \mathrm{~h}+)$ on the caspase-3 activity in normal (white column) and stretched cells (brown column). (D) The cell viability was assessed after caspase-3 was inhibited ( 0 and $36 \mathrm{~h}+$ ), using a Cell Counting Kit-8 assay in normal (white column) and stretched cells (brown column). (E) Apoptosis was detected using aby flow cytometric Annexin V/PI assay. Representative flow cytometry dot plots of CESCs after double staining with Annexin V-FITC and PI are displayed. (F) Apoptotic indices of CESCs from E. Static CESCs (0 h) were used as a control. +, group incubated with caspase inhibitor Z-VAD-FMK. ${ }^{\mathrm{P}} \mathrm{P}<0.05$ vs. control group; ${ }^{*} \mathrm{P}<0.05$ vs. $0 \mathrm{~h}$ group; ${ }^{*} \mathrm{P}<0.05$ vs. $36 \mathrm{~h}$ group. CESCs, cartilage endplate-derived stem cells; Bcl-2, B-cell lymphoma 2; FITC, fluorescein isothiocyanate; PI, propidium iodide; Bak, Bcl-2 antagonist killer protein; Bax, Bcl-2-associated X protein; Bcl-xl, Bclextra large protein.

cysteinyl aspartate-specific proteases that are highly evolutionarily conserved in multicellular organisms and function as central regulators of apoptosis. As a member of this family, caspase- 3 has been identified as a key mediator of apoptosis in most cells (11). The extrinsic and intrinsic apoptotic pathways converge at caspase- 3 , which orchestrates the dismantling of diverse cell structures through cleavage of specific substrates.

The present study confirmed that BNIP3 was expressed at a low level in static CESCs, while a cyclic stretch upregulated BNIP3 expression and downregulated $\mathrm{Bcl}-2$ expression in a time-dependent manner. CCK-8 and flow cytometric assays demonstrated that a cyclic tensile stretch decreased the cell viability and increased apoptosis of CESCs, which was consistent with the results of previous studies (24). Furthermore, the present study demonstrated that a $20 \%$ cyclic stretch activated the expression of caspase-3 in CESCs, which probably contributed to the increase in apoptosis. Caspase-3 inhibitor abrogated the stretch-induced decrease in cell viability and increase in apoptosis at $36 \mathrm{~h}$, when cell apoptosis was at a high level. However, no unstretched control group at time-points 12-48 h that was kept in the stretching device was included, and therefore, the contribution of the effect of being kept in the stretching device to cell apoptosis and decrease in viability could not be assessed. This should be assessed in a future study.

Taken together, the present study suggested that BNIP3 contributed to the regulation of cyclic stretch-induced apoptosis of CESCs in an in vitro model. These results implied that blocking of BNIP3 may improve the tolerance of CESCs to abnormal stretching and delay the process of intervertebral disc degeneration as a potential preventive or treatment strategy. 


\section{Acknowledgements}

This study was funded by the National Natural Science Fund (grant no. 81272028).

\section{References}

1. Haldeman S, Kopansky-Giles D, Hurwitz EL, Hoy D, Mark Erwin W, Dagenais S, Kawchuk G, Stromqvist B and Walsh N: Advancements in the management of spine disorders. Best Pract Res Clin Rheumatol 26: 263-280, 2012.

2. Wieser S, Horisberger B, Schmidhauser S, Eisenring C, Brügger U, Ruckstuhl A, Dietrich J, Mannion AF, Elfering A, Tamcan $\mathrm{O}$ and Müller U: Cost of low back pain in Switzerland in 2005. Eur J Health Econ 12: 455-467, 2011.

3. Freemont AJ: The cellular pathobiology of the degenerate intervertebral disc and discogenic back pain. Rheumatology (Oxford) 48: 5-10, 2009.

4. Schwarzer AC, Aprill CN, Derby R, Fortin J, Kine G and Bogduk N: The relative contributions of the disc and zygapophyseal joint in chronic low back pain. Spine (Phila Pa 1976) 19: 801-806, 1994

5. Schwarzer AC, Aprill CN and Bogduk N: The sacroiliac joint in chronic low back pain. Spine (Phila Pa 1976) 20: 31-37, 1995.

6. Battié MC, Videman T, Levalahti E, Gill K and Kaprio J: Genetic and environmental effects on disc degeneration by phenotype and spinal level: A multivariate twin study. Spine (Phila Pa 1976) 33 2801-2808, 2008.

7. Stokes IA and Iatridis JC: Mechanical conditions that accelerate intervertebral disc degeneration: Overload versus immobilization. Spine (Phila Pa 1976) 29: 2724-2732, 2004.

8. Boos N, Weissbach S, Rohrbach H, Weiler C, Spratt KF and Nerlich AG: Classification of age-related changes in lumbar intervertebral discs: 2002 Volvo Award in basic science. Spine (Phila Pa 1976) 27: 2631-2644, 2002.

9. Urban JP, Smith S and Fairbank JC: Nutrition of the intervertebral disc. Spine (Phila Pa 1976) 29: 2700-2709, 2004.

10. Ariga K, Miyamoto S, Nakase T, Okuda S, Meng W, Yonenobu K and Yoshikawa $\mathrm{H}$ : The relationship between apoptosis of endplate chondrocytes and aging and degeneration of the intervertebral disc. Spine (Phila Pa 1976) 26: 2414-2420, 2001.

11. Fiers W, Beyaert R, Declercq W and Vandenabeele P: More than one way to die: Apoptosis, necrosis and reactive oxygen damage. Oncogene 18: 7719-7730, 1999.

12. Carson DA and Ribeiro JM: Apoptosis and disease. Lancet 341: 1251-1254, 1993

13. Gruber HE and Hanley EN Jr: Analysis of aging and degeneration of the human intervertebral disc. Comparison of surgical specimens with normal controls. Spine (Phila Pa 1976) 23: 751-757, 1998.
14. Ariga K, Yonenobu K, Nakase T, Hosono N, Okuda S, Meng W, Tamura Y and Yoshikawa H: Mechanical stress-induced apoptosis of endplate chondrocytes in organ-cultured mouse intervertebral discs: An ex vivo study. Spine (Phila Pa 1976) 28: 1528-1533, 2003.

15. Huang B, Liu LT, Li CQ, Zhuang Y, Luo G, Hu SY and Zhou Y: Study to determine the presence of progenitor cells in the degenerated human cartilage endplates. Eur Spine J 21: 613-622, 2012.

16. Cory S and Adams JM: The Bcl 2 family: Regulators of the cellular life-or-death switch. Nat Rev Cancer 2: 647-656, 2002.

17. Cappello R, Bird JL, Pfeiffer D, Bayliss MT and Dudhia J: Notochordal cell produce and assemble extracellular matrix in a distinct manner, which may be responsible for the maintenance of healthy nucleus pulposus. Spine (Phila Pa 1976) 31: 873-883, 2006.

18. Sowa G and Agarwal S: Cyclic tensile stress exerts a protective effect on intervertebral disc cells. Am J Phys Med Rehabil 87: 537-544, 2008.

19. Lee H and Paik SG: Regulation of BNIP3 in normal and cancer cells. Mol Cells 21: 1-6, 2006.

20. Sassone F, Margulets V, Maraschi A, Rodighiero S, Passafaro M, Silani V, Ciammola A, Kirshenbaum LA and Sassone J: Bcl-2/adenovirus E1B 19-kDa interacting protein (BNip3) has a key role in the mitochondrial dysfunction induced by mutant huntingtin. Hum Mol Genet 24: 6530-6539, 2015.

21. Chen Y, Henson ES, Xiao W, Shome E, Azad MB, Burton TR, Queau M, Sathya A, Eisenstat DD and Gibson SB: Bcl-2 family member Mcl-1 expression is reduced under hypoxia by the E3 ligase FBW7 contributing to BNIP3 induced cell death in glioma cells. Cancer Biol Ther 17: 604-613, 2016.

22. Landes T, Emorine LJ, Courilleau D, Rojo M, Belenguer P and Arnauné-Pelloquin L: The BH3-only Bnip3 binds to the dynamin Opal to promote mitochondrial fragmentation and apoptosis by distinct mechanisms. EMBO Rep 11: 459-465, 2010.

23. Ray R, Chen G, Vande Velde C, Cizeau J, Park JH, Reed JC, Gietz RD and Greenberg AH: BNIP3 heterodimerizes with $\mathrm{Bcl}-2 / \mathrm{Bcl}-\mathrm{X}(\mathrm{L})$ and induces cell death independent of a Bcl-2 homology 3 (BH3) domain at both mitochondrial and nonmitochondrial sites. J Biol Chem 275: 1439-1448, 2000.

24. Xu C, Hao Y, Wei B, Ma J, Li J, Huang Q and Zhang F: Apoptotic gene expression by human periodontal ligament cells following cyclic stretch. J Periodontal Res 46: 742-748, 2011.

This work is licensed under a Creative Commons Attribution-NonCommercial-NoDerivatives 4.0 International (CC BY-NC-ND 4.0) License. 